\title{
STUDENTS' REFLECTION ON WORK-BASED EXPERIENCE: CONNECTING SOCIAL LEARNING TO THEORY AND PRACTICE AT A SOUTH AFRICAN UNIVERSITY OF TECHNOLOGY
}

\author{
Pulane Adelaide Molomo \\ Dr., Central University of Technology, Free State, South Africa, pmolomo@cut.ac.za
}

\begin{abstract}
Employers often complain about a lack of certain capabilities and experience amongst graduates who are entering the job market. This paper examines ways in which students' workplace reflections enable-social learning as well as equipping them with strategies for future careers. The aim was to enable students to link theory and practice and reflect on social learning experiences. A purposive sample of 30 students at the selected University of Technology and 15 employers were used as participants in the study. A selfadministered questionnaire was used to collect data from the 15 employers. Qualitative rich and relevant data on students' experiences at the workplace were gathered through interviews, focused group discussions and assessment of their portfolios of evidence. Quantitative data with regards to employers' assessment of traits needed at the workplace and the relevancy of curriculum were gathered through a 4point Likert scale. Qualitative data analysis involved systematically sorting and categorising data into common themes whilst quantitative data was analysed statistically. Students' acquisition of relevant skills, knowledge, values and attitudes, and their interaction with diverse people associated with workplace experience, were found to be beneficial for their careers. Preparatory and post activities accompanying the process of Work Integrated Learning (WIL) were also found to be helpful in preparing students to adjust to the workplace environment. It is thus concluded that the Work Integrated Learning module be incorporated in different programmes at the university of technology to give students the opportunity to integrate theory and practice, to get a social space to learn from others experiences and enhance graduate attributes. The significance of this study provides insight about placing students in a working environment for social learning experiences and to be able to link theory and practice. It is recommended that WIL be included in most of the programmes to increase students' chance of success as well as improving competences that employers found lacking amongst them. Challenges on placement of students during the high levels Covid19 pandemic opened avenues for future research on how technological platforms and innovation hubs can be used to help students acquire work-based experiences.
\end{abstract}

Keywords: Preparation, portfolio of evidence, reflection, social learning, workplace experience

\section{INTRODUCTION}

The increasing complexities and technologies in work-related institutions including the socio-economic demands of the $21^{\text {st }}$ century requires students to be equipped with the relevant knowledge and skills and with work-based social learning experiences. Work Integrated Learning (WIL) is a global concept used in different parts of the world and is applicable in both global and local contexts to enable the application of theoretical knowledge in practical work situations (Billet (2011). It thus creates a trajectory for students to navigate the world of work to enhance competences and to learn from others' experiences. In British Columbia for example, a comparative matrix was developed to compare various forms of WIL (Johnson, McRae, \& Maclean, 2016). In Australia the government supports the Teaching and Learning office in 
developing a global perspective about WIL (Leask and Wallace 2011. In South Africa, as guided by the South African Higher Education Qualifications Framework (HEQF) of 2007 higher education institutions are mandated to include the WIL component as an offering in different programmes. Emerging from Technikons and inherent in Universities of Technology (UoTs) is a strong vocational orientation that ties with industries to enable students, workplace learning opportunities. However, part of the criticism levelled against graduates by employers is higher education 's failure to produce graduates who are innovative. Therefore, WIL is used in universities of technology (UoTs) as to expose students with complex industries experiences where they ostensibly apply knowledge and technical skills and learn from others. In support of learning from others the Skills Development Act (Act 97 of 1998) also stipulates that part of the learning programme unit should include a work experience component for students to get insight into real-world operations. Thus, the completion of a qualification in universities of technology requires students to complete work-based practice which is covered by a submission of portfolio of evidence (PoE).

\section{LITERATURE REVIEW}

\subsection{Work Integrated Learning (WIL)}

The practical aspects of a qualification find expression through internships, partnerships, service learning, experiential learning, cooperative education, and Work-Integrated Learning (Kennedy, Billett, Gherardi \& Grealish, 2015). Subsequently, activities emanating from these different forms of work-based learning bring synergy between unrelated entities to enhance learning, innovation, problem solving and communication (Kennedy et al., 2015). Work Integrated Learning thus serves as a guiding principle to enhance employability and work-related attributes needed in the market amongst aspiring graduates (Small, Shacklock \& Marchant, 2018). Furthermore, the world of work establishes a learning connection between foundational principles and skills, as well as attributes to ensure that graduates become employable (Kruss, 2004). This means that work-based learning complements learning found in institutions of higher learning to provide conditions for planned activity to improve students' development (Kennedy et al., 2015). WIL provides experiences which enable individual students the opportunity to shape attitudes, to learn more about practice and to clarify unrealistic views about the job market and other work-related social aspects (Paterson, 2017; Adrian, 2017). Admittedly, Bandura (1977) postulates that social learning is an important enabler for individual's cognitive and social development. Thus, social interactions at the workplaces create social learning experiences in acquiring knowledge from significant others (Carolan, 2013).

\subsection{Work Integrated Learning (WIL)'S Role in Linking Theory and Practice}

Most curricula embed occupational curricula and theory which is characterised by a scientific and systematic ordering of information (Maton, 2006; Wheelahan, 2010). WIL facilitates the link that enables the successful completion of a qualification which needs graduates to possess factual knowledge and skills including social learning experiences. A curriculum that embraces theory and practice creates an opportunity for both knowledge and occupational movement, which, in turn, establishes the acquisition of a mix of different knowledge types (Barnett, 2006). Significantly, Work-based learning provide students with the relevant practical experience they need and new experiences to reflect on (Beard and Wilson, 2013). This implies that different resources that are available at the workplace and employees' social culture that could not be found in institutions of learning but, are found in workplaces allows students to understand content and context better. Espoused in the Skills Development Act (Act 97 of 1998) is the emphasis on exposing students to the real world. Work-based learning as part of the practical component of the curriculum of various programmes in universities of technology therefore navigates the process of linking knowledge emanating from disciplines with practice to deepen students' understanding (CHE, 2011). Therefore, role players such as employers, institutions of higher learning, civil society and students have different responsibilities and roles to perform. Besides, students observe how things are done which assists them to broaden their scope of understanding the world in general and to reflect on those experiences. Reflection then becomes an important tool to be used to share experiences learnt to connect knowledge and practice as well as making sense of the social environment of the workplace (Williamson 1997).

\subsection{Work Integrated Learning (WIL) and Graduate Attributes}

As pointed out by (Giroux, 2002) most of the governments support business ideas for national economic growth including global citizenry as one of the graduate attributes. Even though graduate attributes have been introduced within and across curricula as core values and skills that students need to possess upon graduation in most universities, some studies have shown some gaps in the skills that students acquire in institutions of higher learning which may mean that labour demands are not fully satisfied (Griesel \& Parker, 2009). This implies that the labour market platforms need to be understood not only as a space for the technological application of skills, but also as a space for the exchange of different types of knowledge, 
constant research, decision making and social learning. Besides, opportunities opened through WIL, there are other unanswered questions and other aspects of placement that are not known which individual students can discover and include them in their diary entries during placements (Dean, Sykes, \& Turbill, 2018).

The following are some of the graduate attributes that employers are looking for: good communication in English; comprehension of the business and working environments; proficiency in the use and production of field-specific and general knowledge; problem solving, self-confidence, self-efficacy and autonomy (Griesel \& Parker, 2009). All these attributes are important, but they can better be realised when critical thinking skills are given effect by students' ability to reason and reflect on their experiences (CHE, 2013). Attributes such as moral leadership, cultural and emotional intelligence, as well as global citizenship also enhance students' knowledge about reality in a holistic manner (Coetzee, Botha, Nienaber \& Holtzhausen, 2012). WIL thus, gives students the opportunity to learn about social practices outside the four walls of the classroom. Undoubtedly, the world and the workplace need graduates who can influence the world positively, save business costs and sustain the organisation over the long term (Griesel \& Parker, 2009). Therefore, the generic graduate attributes contribute with additional soft skills to mould the type of graduate needed by the labour market.

\subsection{Work Integrated Learning (WIL) and Social Learning}

Social learning is perceived as another learning experience that can be associated with global citizenry and social change. It prepares students to become critical risk-taking citizens who can interpret and analyse issues in the world of work and in the civic space (Nussbaum, 2011). WIL thus, embeds opportunities that contributes towards students' work-readiness and the ability to cope with diversity (CHE, 2011). As a result, students are placed in industries, private businesses, government departments and Non-Profit Organisations to strengthen the base of their knowledge and skills to engage with others and widen their social learning experiences (Davids, Theron \& Maphunye, 2008). The implication is that learning from significant others contributes towards recognising other pockets of knowledge to enable students not to look only at material gains in the workplace, but to learn about the culture of work, ethical principles, professional conduct and how to communicate at a professional level (Martinez, 2010). In support of WIL activities, the World Economic Forum (WEF, 2016) also recommends that employers should open their doors to become centres of development to allow students to sharpen their skills and knowledge instead of waiting for students to complete their studies and only then absorb them as unprepared employees.

Although work-based learning does not necessary translate to employment, it is also a social learning experience that brings awareness about employment prospects for the students (Paterson, 2017). This implies that students' interaction with employers and employees at the workplace allows them a space to learn how diversity is embraced at workplace environment including other traits that contribute towards a conducive environment of productivity, performance, and commitment. Unquestionably, a proper link with practice through WIL or experiential learning is necessary to achieve both curriculum goals and skills (Pink, 2005; Roberts, 2012). For example, work-based learning in fields of study such as Radiography, Industrial Radiography, Fashion Design and Clothing, Graphic Design, Education, Engineering, Public Management, Community Development, Somatology, and other fields of study allows work-based learning to make more practical sense.

\subsection{Theoretical framework}

A theoretical framework refers to assumptions, ideas and concepts grounding the study. (Neuman (2011). This study adopts a hybrid of contemporary constructivist theories of Kolb (1984), and Schön (1987) which are influenced by Dewey's (1933) model of education. Dewey's model attempted to eliminate the separation of the real-world experience from theory taught in the classroom by advocating for a relationship between theory and practice to enhance students' experiences. In this paper concepts of constructivists theories on learning highlight the success of high levels of learner engagement with real life situations that leads to real unforgettable learning experiences (Hickson,2011).

Whilst Kolb's (1984)'s reflective model place emphasis on experiential learning Schon (1987) theory focuses on reflecting on practice. Kolb (1984) experiential learning refers to learning by observing others in a practical situation and that highlights the importance of the social environment as another platform of learning. In Schon's case the idea of a reflective practitioner place emphasis on the exposure to practice and to critically reflect on what is done right and to identify areas that needs to be improved. In the case of Dewey (1933) the focus is on active learning, inquiry and the relationship between theory and practice which translate to a contextual whole. The link between the two separate components that is theory and practice as highlighted by (Kennedy et al., 2015) becomes significant in revealing the interaction between the objective 
angle emanating from theory and the nature of experience which bears elements of subjectivity or what can be referred as the social learning context. The idea of the mixed method approach in addressing the research question through tools that reflects on the objective and the subjective lenses of looking at reality becomes meaningful in drawing out the relationship between the two different worlds that constitute a whole.

The common element in all the three theories is the idea of learning from theory and social learning experiences of others in the workplace can be done either through observation or immersing oneself in a real-world situation. The main idea is to link theory and practice which (Kennedy et al., 2015) refers to as unrelated entities which are brought together to enhance learning, innovation, problem solving, and communication. WIL therefore becomes a tool which directs students' path towards the realisation of certain competences, skills, knowledge, experience as well as enabling them to critically reflect on practice. It further contributes towards the realisation of certain educational outcomes inherent in in the curriculum and assessment of various disciplines. Although Kolb (1984) brings out the importance of experience, reflecting on what works and what does not work remains one of the key principles in his theory. Thus, the world of work is found to be the appropriate site for students to enhance their knowledge and skills and to critically reflect. Feedback given in the form of reflection and through student PoE is significant to facilitators in getting feedback that will enable them to reflect about curriculum relevancy, assessment methods and areas that need to be improved to heighten the overall development and success of students and economic growth.

\section{AIM OF THE STUDY}

The aim was to enhance the link between theory and practice to enable students to learn and reflect on experiences gathered at the workplace.

\subsection{Research Question}

What impact does WIL have in influencing students' success in linking theory and practice and acquiring social learning experiences?

\subsection{Research Objectives}

1. To establish the benefit of students' preparation and support before and during the WIL process.

2. To assess the extent to which WIL enable students to realise the link between theory and practice and the value of learning from others?

3. To determine whether students possess and are developed on traits and capabilities that employers need?

\section{RESEARCH DESIGN AND METHODOLOGY}

\subsection{Research Design}

This study adopted a mixed method approach to collect data to bring about an objective element to the findings as well as enriching data. The quantitative, non-experimental information about the employers' feedback on traits and capabilities that students are expected to have when they join the world of work were gathered by means of a 4-point Likert scale and analysed statistically. A review of literature preceded an interpretive paradigm which was influenced by participants' experiences through interviews and two focused group discussions (FDGs) consisting of eight members each, using semi-structured questions on how the participants experienced the world of work (Patton 2015; Denzin \& Lincoln 2012). Participants' narratives were transcribed and manually coded into themes, Permission to conduct the interviews was sought from the institution concerned and the researcher provided participants with the objectives of the study both verbally and in writing.

Students' reflections about experiences they gathered at the workplace were guided by the lecturer's systematic questions and a set of criteria that allowed them the opportunity to discuss the impact of WIL. Their individual experiences, workplace dynamics, the value of WIL pre-preparatory activities and traits that made them stand out and more likely to be hired were also captured. They reflected on the value of preparatory activities and guest lecturers that prepared them prior the work placement about professional conduct. Their experiences were captured in reflective reports and discussed in the form of verbal reports in the presence of peers and the lecturer prior to individual submission of portfolios of evidence (PoEs) which were also used as part of the assessment strategy.

\subsection{Sample and Sampling}

As asserted by (Awang \& Noryanti Muhammad, 2012) the sampling method is of great value in determining 
the trustworthiness and validity of the research findings about the phenomenon under investigation. Out of total number of 90 students, the study sample was limited to a purposefully selected group of 30 students who were impacted by WIL placements at the selected University of Technology. They included males and females, aged between 21 and 25, all of whom were purposively selected to represent the population of students who were relevant to the research design. To guard against bias 15 employers where students were placed, were provided with quantitative questionnaires. Although follow ups were made only 10 filled responses to questionnaires were received. The questionnaire consisted of 10 questions which provided feedback about common skills and knowledge student had which satisfied employers including some competences and capabilities which were found lacking amongst some of the students.

\subsection{Methods}

Both quantitative and qualitative data were collected to complement each other and to bring in the element of reliability and trustworthiness. To obtain quantitative data, use was made of a 4-point Likert scale, which statistically measured the relevancy of curriculum and traits needed by employers. Interviews and two focused groups discussions (FDGs) consisting of eight members each were conducted to collect rich qualitative data (Merriam \& Tisdell (2016). FDGs were facilitated by the researcher using semi-structured questions to enable each participant a platform to reflect on their experiences. Portfolio of evidence were examined by relevant lecturers to assess reporting and reflection skills which corroborated students' experiences were availed to the researcher to confirm the information.

\subsection{Data Analysis}

Quantitative data obtained through the Likert scale on employees' assessment of students' capabilities was coded and analysed statistically. Qualitative data obtained from participants through interviews and focus groups discussions elicited rich qualitative data. Such data were recorded, transcribed, and systematically sorted, categorised into common emergent themes, and analysed thematically through content analysis (Saldana, 2016).

\section{FINDINGS}

The following themes emerged from analysing participants' responses on interviews and FGDs. Each theme is subsequently discussed in more details:
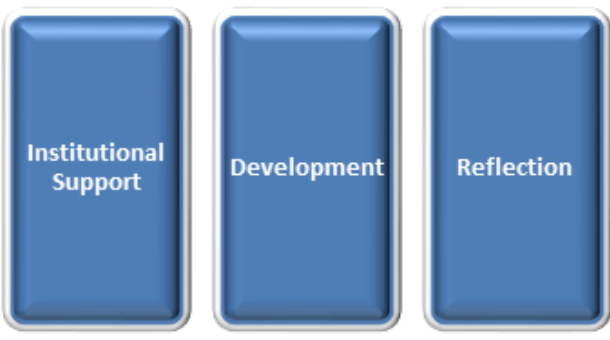
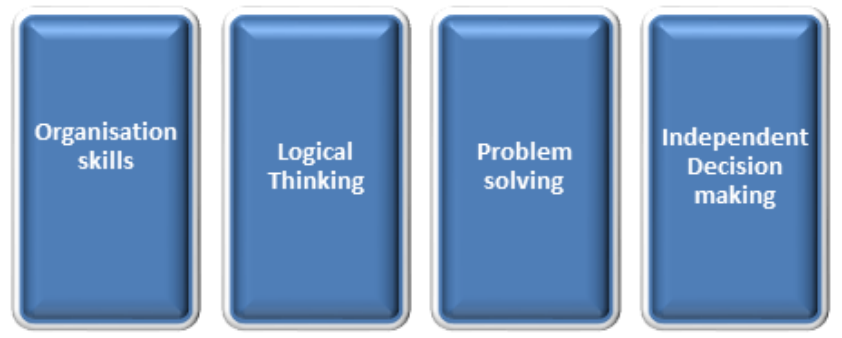

Fig 1: Emergent themes

\subsection{Preparation Of Students And Institutional Support}

The Focused Group Discussions (FGDs) revealed the importance of institutional preparations, guidance, and students' support. Preparatory sessions done prior to placements prepared them about punctuality, professional conduct. The declaration of commitment placed in their respective PoEs reminded them of their purpose. [FGDs]

Also highlighted was the importance of a tick box template that referred to conduct, ethical principles, dress code, values, attributes, and leadership skills which accompanied the preparations to reinforce behaviour. Activities done by lecturers and the office of the WIL ensured smooth adjustment at the workplace. [FGDs]

The following quotes include the benefits of WIL preparations:

"Guest lecturers made it easier for me to know the purpose of placement which is to learn". [Participant 1]

\subsection{Reflection on Experiences}

Reflection can be used in many ways to share experiences, lessons learned or reflect about practice (cf. Williamson, 1997). Participants reflected on how WIL contributed in building positive traits. 
"WIL taught me high standards of performance when executing tasks which instilled diligence and a change on how I approach my work and life in general". [Participant 1]

Productivity was flagged. "I learned to move out of my comfort zone and see what the real world is like whereby productivity is prioritised. [Participant 2]

Commitment and urgency were flagged. "Work placement was a wonderful experience that instilled a sense of commitment and urgency to get the work done". [Participant 2]

Weekly reports and meetings were reported as having created a good foundation for experiencing teamwork and good performance. [Participants 4-10 \& FGDs]

The above responses confirm the assertion made by (cf. Small, Shacklock \& Marchant, 2018; Paterson, 2017; Adrian, 2017). that WIL sharpens desired traits and enhances the prospects of employability.

\subsection{Communication and Other Attributes}

Below are attributes and traits that employers need which literature confirms (cf. Griesel \& Parker, 2009).

Planning and open communication were reported as key. [Participant 1-5]

The quotes below highlight participants' views on attributes that were sharpened.

"I learned to focus on achieve goals. [Participant 6]

"I learnt to embrace diversity and to respect every employee when employees at lower levels displaying a mastery of complex skills and knowledge". [Participant 7]

“Timely completion of tasks dispelled self-doubt and I learned to believe in my abilities". [Participant 9]

"Staff meetings set the tone for weekly and monthly targets which made me to learn the value of time management, planning, organisation and control." [Participant 8]

Other participants reflected on errors they committed when working under pressure and how senior personnel coached them on how to prioritise.

The above excerpts support WIL in enhancing attributes that are needed at workplace amongst aspiring graduates (cf. Small et al., 2018).

\subsection{Learning and Development}

On the question about to what extent reflection impacted on self-development, students had this to say,

"I learnt to to communicate in a professional way". [Participant 1]

Motivation was flagged. "I was inspired by the achievement of other employees". [Participant 2]

The aspect of responsibility as one of the graduate attributes was also mentioned.

"I learned responsibility of carrying certain tasks independently." [Participant 3]

A better understanding of content was flagged. "I understood theory better by apply it in practice." [Participant 4]

A perspective to life was developed. "I learned to see the world differently. [Participant 5]

Integrating theory and practice at the workplace deepened knowledge about the discipline." [Participant 6]

Use of resources flagged. The workplace taught me to use resources well. [Participant 7-10 \& FGDs]

The excerpts above confirm that WIL complements learning found in institutions of higher learning and enhance students' learning and development (cf. Kennedy et al., 2015).

\subsection{Changed Perceptions and Attitude}

The except below indicates perceptions and attitude change:

"Interacting with other employee taught me to respect authority and diversity." [Participant 1]

A relationship between time management and productivity was also highlighted:

"I learned how time was valued in determining productivity". [Participant 2]

"I learned about perseverance, focus and hard-work,." said one of the participants [Participant 3] 
"I learned that hard work pays when seeing commitment displayed by directors. [Participant 4]

\subsection{Journal Entries and Organisation}

Students not only reported their experiences verbally. They also shared how they used their learning journal entry books and diaries.

"The learning journal entry book left me with a sense of excitement and organisation in recording all my daily experiences and I reflect on them without missing anything." [Participant 1]

Guidelines provided guidance. "Guidelines given to us on how to organise our portfolio made it possible for me to organise my report systematically." [Participant 2]

The excerpt reflects on organisational policy. "Conflicts were addressed according to HR procedures." [Participant 4]

Students mentioned how they critical reflected on lessons learned. Excerpts from the interview transcripts are as follows:

"Critical reflection guided me in ordering my thoughts to report my experience" (Participant 5)

"The critical reflection guide helped me to elaborate my reflection better." said (Participant 6)

Table 1: A Distribution of employers' responses to each statement

\begin{tabular}{|c|c|c|c|c|}
\hline \multirow[t]{2}{*}{ Statement Number } & 1 & 2 & 4 & 5 \\
\hline & $\begin{array}{l}\text { Strongly } \\
\text { Agree }\end{array}$ & Agree & Disagree & $\begin{array}{l}\text { Strongly } \\
\text { Disagree }\end{array}$ \\
\hline $\begin{array}{l}\text { 1. Students can think } \\
\text { innovatively. }(+)\end{array}$ & $0(0 \%)$ & $2(20 \%)$ & $6(60 \%)$ & $2(20 \%$ \\
\hline $\begin{array}{l}\text { 2. students can make } \\
\text { independent decisions. }(+)\end{array}$ & $1(10 \%)$ & $3(30 \%)$ & $4(40 \%)$ & $2(20 \%$ \\
\hline $\begin{array}{l}\text { 3. students can solve problems } \\
\text { independently. }(+)\end{array}$ & $1(10 \%)$ & $2(20 \%$ & $4(40 \%)$ & $5(50 \%)$ \\
\hline $\begin{array}{l}\text { 4. students are lacking in } \\
\text { analytical skills. (-) }\end{array}$ & $8(80 \%)$ & $1(10 \%)$ & $1(10 \%)$ & $0(0 \%)$ \\
\hline $\begin{array}{l}\text { 5. students can communicate } \\
\text { well. }(+)\end{array}$ & $7(70 \%)$ & $3(30 \%)$ & $0(0 \%$ & $0(0 \%)$ \\
\hline $\begin{array}{l}\text { 6. students cannot manage } \\
\text { time well. }(-)\end{array}$ & $10 \%)$ & $1(10 \%)$ & $3(30 \%)$ & $5(50 \%)$ \\
\hline $\begin{array}{l}\text { 7. students cannot link theory to } \\
\text { practice. (-) }\end{array}$ & $2(20 \%)$ & $1(10 \%)$ & $4(40 \%)$ & $3(30 \%)$ \\
\hline $\begin{array}{l}\text { 8. students cannot manage } \\
\text { conflicts. }(-)\end{array}$ & $4(40 \%)$ & $1(10 \%)$ & $3(30 \%)$ & $2(20 \%)$ \\
\hline $\begin{array}{l}\text { 9. students can work under } \\
\text { pressure. }(+)\end{array}$ & $4(40 \%)$ & $3(30 \%)$ & $2(20 \%)$ & $1(10 \%)$ \\
\hline $\begin{array}{l}\text { 10. students can work as a team. } \\
(+)\end{array}$ & $6(60 \%)$ & $2(20 \%)$ & $1(10 \%)$ & $1(10 \%)$ \\
\hline
\end{tabular}

The table above consists of number of responses listed from 1-10 consisting of positive and negative statements.

(+) represents positive worded statements 
(-) represents negative worded statements

${ }^{*}$ numbers are converted to percentages

\section{+ Statement 1: Students can think innovatively.}

A relatively high number, $60 \%$ of respondents disagreed that students could think innovatively, $20 \%$ strongly disagreed whilst $20 \%$ agreed.

\section{+Statement 2: students can make independent decisions.}

A relatively high number, $40 \%$ of respondents disagreed that students could make independent decisions. $20 \%$ strongly disagreed, $30 \%$ agreed and $10 \%$ strongly agreed.

\section{+ Statement 3: students can solve problems independently.}

Most of the respondents disagreed to the statement that students can solve problems independently, $60 \%$ strongly disagreed, $30 \%$ disagreed and only $10 \%$ agreed to the statement.

\section{-Statement 4: students are lacking in analytical skills.}

Most of the respondents agreed to the statement that students are lacking in analytical thinking. A relative high number of respondents strongly agreed $80 \%, 10 \%$ agreed, whilst only $10 \%$ disagreed to the statement.

+ Statement 5: students can communicate well.

A relatively high number of $70 \%$ of the respondents strongly agreed to the statement, $20 \%$ agreed whilst $10 \%$ disagreed to the statement

-Statement 6: Students cannot manage time well.

On this criterion, $50 \%$ of the respondents strongly disagreed to the statement that students cannot manage time well whilst $30 \%$ disagreed. Another $10 \%$ strongly agreed to the statement whilst the other $10 \%$ agreed.

\section{-Statement 7: students cannot link theory and practice.}

$30 \%$ of the respondents strongly disagreed to the statement, $40 \%$ disagreed, $10 \%$ agreed whilst $20 \%$ strongly agreed.

\section{Statement 8: students cannot manage conflicts.}

$40 \%$ of the respondents strongly agreed to the statement that students cannot manage conflict, $10 \%$ agreed, $30 \%$ disagreed and $20 \%$ strongly disagreed.

\section{+Statement 9: students can work under pressure.}

$40 \%$ of the respondents strongly agreed, $30 \%$ agreed, $20 \%$ disagreed and $10 \%$, strongly agreed to the statement that students can work under pressure.

\section{+Statement 10: students can work as a team.}

A relatively high number of respondents agreed to the statement that students can work as a team, about $60 \%$ strongly agreed to the statement, $20 \%$ agreed, $10 \%$ disagreed whilst the other $10 \%$ of respondents strongly disagreed.

\section{DISCUSSION OF THE FINDINGS}

Information gathered from focused showed some grey areas with respect to understanding some concepts of theory, self-discipline, commitment, and the ability to cope with various social challenges. The findings revealed that preparation of students laid ground rules to mould students' behaviour and to adjust to the workplace environment. Work Integrated Learning (WIL) makes provision for learning activities that contributes towards students' development (Kennedy et al., 2015). The findings revealed that work experience is a subjective and individual experience, which affords students the opportunity to learn more about practice and to clarify unrealistic views about the job market (Paterson, 2017; Adrian, 2017). Thus, students' exposure to difficult tasks in the real world teaches them to cope with pressure and to learn from others.

Furthermore, WIL revealed the idea that students were able to learn more and engage at an emotional level. For example, in subjects such as Design and Clothing, students developed attitudes towards some clothing brands and designs, in such contexts, practical engagement is also credit-bearing and forms part of the assessment criteria. Knowledge and skills acquired by learning from others experiences in linking theory and 
practice revealed to have contributed towards understanding some theoretical concepts in a much better light. Work placements also revealed the role played by employers in creating opportunities for students to have lived experiences about the world of work and to be mentored whilst students seize the opportunity of shaping up certain traits as well as unleashing their potential was also uncovered. The idea of shaping students' competences is confirmed by (Kruss 2004) assertion about the connection formed between foundational principles and skills, including the acquisition of relevant attributes that ensure prospects of employability.

The findings have shown that students were rated as competent and received the highest percentage in areas such as time management, linking theory and practice, teamwork, conflict management and the ability to work under pressure. a relative high number of students showed a great potential. However, a high number of students were poorly graded in other items such as, innovative skills, analytical thinking skills and the ability to solve problems independently. Such grey areas showed that improvements need to be done in those areas and further confirmed the assertion that gaps in skills and knowledge that students acquire in institutions of higher learning disrupt productivity and contribute to labour demands not being fully satisfied (see Griesel \& Parker, 2009). Analytical thinking and inquiry which also forms one of the components of Dewey's educational model (see Dewey, 1933) need to be prioritised as it lays the foundation for logical and innovative thinking skills. The development of higher thinking capabilities in the curriculum is key in preparing students for the $21^{\text {st }}$ century world in becoming innovative, solving problems, using resources properly, saving the world from socio-economic challenges and sustain organisations on a long-term base (cf. Griesel \& Parker, 2009).

Similarly, students discover other unanswered questions and other aspects of the work environment that are not known and not covered in theories. which work placements allows them to discover and get the opportunity to include the information in their diary entries during work placement (Dean, Sykes, \& Turbill, 2018). The revelation is that PoEs and entry diaries were found to be beneficial in enabling students to record and capture all their experiences and reflect including negative elements such as favouritism, conflicts, and unequal treatment of employees. The researcher suggests that preparation, support, and monitoring of students prior and during their work placements is necessary to improve practices and curriculum delivery.

\section{CONCLUSION}

This study contributes towards increasing students' understanding about the link between theory and practice and the role played by the world of work in shaping up attitudes. It further highlights areas that needs to be improved. The interest in work employability knowledge, skills, and graduate attributes, including social learning enables students to adjust to work dynamics and the culture of the real world. These are all important qualities that steer students to right direction of balancing theory and practice and adjusting to some of the social experiences that accompanies the work environment. Gaps about skills and knowledge that were found to be poorly developed by employers validates the importance of placing students in workplace environments to give to exposure areas that needs neds to be improved Students also gathered work experiences which contributed towards improving employability in the long run. This implies that the relationship between institutions of learning and industries is significant towards prepare students to fit well in the workplace environment.

\section{IMPLICATIONS}

Work-Integrated Learning as a niche area for universities of technology should be sustained to increase students' social learning experiences and work preparedness. The implication about partnerships forged between higher institutions of learning, industries and other sectors enables the application of knowledge and skills in real life situations. Furthermore, gaps of knowledge and skills identified by employers during WIL placements have implications to highlight curriculum relevance and alignment with trends in the marketplace. Due to challenges brought by Covid19 future research studies should focus on how digital technologies and innovation hubs can be used optimally to enhance levels of high levels of thinking capabilities to escalate innovation.

\section{REFERENCE LIST}

Adrian, M. (2017). "Determining the skills gap for new hires in management: Student perceptions vs employer expectations". International Journal of Innovation Education and Research, 5(6), $139-147$. 
Awang, G., A. \& Noryanti Muhammed S., K., S. (2012). "Research design and data analysis in social science research". Malaysia: Pahang University.

Bandura, A. (1977). Social learning theory. Englewood Cliffs, NJ: Prentice Hall.

Barnett, M. (2006). "Vocational knowledge and vocational pedagogy". In Knowledge, curriculum, and qualifications for South African further education. M.F.D. Young, \& J. Gamble, Eds. Pretoria: HSRC, 143-157.

Beard, C. \& Wilson, J., P. (2013). "Experiential learning: a handbook for education training and coaching". (3rd ed.). London, UK: Kogan Page Publishers.

Billet, S. (2015). Integrating practice-based experiences into higher education, Springer, Dordrecht, The Netherlands.

Billett, S. (2011). Curriculum and pedagogic bases for effectively integrating practice-based experiences. Sydney: Australian Learning and Teaching Council

Carolan, B. V. (2013. "Social network analysis and education: Theory, methods and applications". Los Angeles, CA: Sage.

Coetzee, M. Botha, J. Nienaber, H \& Holtzhausen, N. (2012). "Developing student graduatedness and employability: Issues, provocations, theory and practical guidelines". Johannesburg: Knowres Publishing.

Council for Higher Education, (2011). "Work-Integrated Learning": Good Practice Guide. Pretoria: Government printing.

Council on Higher Education [CHE]. (2013). "A proposal for undergraduate curriculum reform in South Africa: The case for a flexible curriculum structure". Pretoria: Government printing.

Creswell, J.W. (2013). Qualitative inquiry and research design: choosing among five approaches, 3rd ed. Thousand Oaks, London: Sage Publications.

Davids, I. Theron, F. \& Maphunye, J. (2009). "Participatory development in South Africa: A development management perspective". 2nd ed. Pretoria: Van Shaik.

Dean, B. A Syke, C. Agostinho S. \& Clements, M. (2012). "Reflective assessment in work-integrated learning: To structure or not to structure, that was our question". Asia-Pacific Journal of Cooperative Education.13(2), 103-113

Denzin, N., K. \& Lincoln, Y., S. (2012). "The SAGE handbook of qualitative research". 4th ed. California: Sage publications.

Dewey, J. 1933. "How we think”. Buffalo, NY: Prometheus Books.

Giroux, H. 2002 "Neoliberalism, corporate culture, and the promise of higher education: The university as a democratic public sphere". Harvard Educational Review, vol. 72(4): 425-464.

Griesel, H. \& Parker, B. 2009 "Graduate attributes: A baseline study on South African graduates from the perspective of employers". Pretoria: Higher Education South Africa.

Johnson, N., McRae, N., \& Maclean, C. (2016). The Development of a Comparative Matrix of Forms of Work Integrated Learning and Work-Integrated Education (WIL/WIE) within the Province of BC, Canada. Paper presented at the 2nd WACE International Research Symposium on Cooperative and WorkIntegrated Education, Victoria, BC, Canada.

Hickson, H. (2011). Critical reflection: Reflecting on learning to be reflective. Reflective Practice: International and Multidisciplinary Perspectives 12(6), 829-839.

Kennedy, M. Billett, S. Gherardi, S. \& Grealish, L. (2015). "Practice-based learning in higher education: jostling cultures". In M. Kennedy, S. Billett, S. Gherardi \& L. Grealish (eds.), Practice-based learning in higher education: jostling cultures, pp. 1-14. New York: Springer.

Kolb, D., A (1984). Experiential Learning as the Science of Learning and Development. Englewood Cliffs, NJ: Prentice Hall.

Kruss, G. (2004). "Employment and employability: Expectations of higher education responsiveness in South Africa”. Journal of education policy, vol. 19(6), 673-689.

Marttinez, M.A. (2010). "Learning and cognition: the design of the mind". Upper Saddle River: Person 
Education.

Maton, K. (2006). "On knowledge structures and knower structures". In Knowledge, power, and educational reform. R. Moore, M. Arnot, J. Beck \& H. Daniels, Eds. London: Routledge, 58-73.

McGregor, S.L.T. and Murnane, J.A. (2010). Paradigm, methodology and method: Intellectual Integrity in Consumer Scholarship. International Journal of Consumer Studies, 34(4), 419-427.

Merriam, S.B. \& Tisdell, E.J. (2016). "Qualitative research: A guide to design and implementation". 4th ed. San Francisco: John Wiley \& Sons.

Mezirow, J. (1998). On critical reflection. Adult Education Quarterly, 48(3), 185-199.

Nussbaum, M. (2011). "Creating Capabilities: The Human Development Approach". Belknap Press, Cambridge, MA.

Paterson, R. (2017). "Lecturer and student perceptions of employability skills at a transnational university". Qualitative research in education, vol. 6(3), 241-275.

Patton, Q.M. (2015). "Qualitative research \& evaluation method". 4th ed. London: SAGE Roberts, J. W. 2012. "Beyond learning by doing: Theoretical currents in experiential education". New York: Routledge.

Pink, L. D. (2005). "A whole new mind: why right-brainers will rule the future". New York: Riverhead Books.

Republic of South Africa, (1988). Skills Development Act 97. Pretoria: Government Printers.

Saldana, J. (2016). "The coding manual for qualitative researchers".3rd ed. Thousand Oaks, London: Sage Publications.

Schön, D. A. (1983). "The reflective practitioner: How professionals think in action”. New York: Basic Books.

Schön, D. (1983). The Reflective Practitioner. San Francisco: Jossey-Bass.

Small, L., Shacklock, K., \& Marchant, T. (2018). Employability: a contemporary review for higher education stakeholders. Journal of Vocational Education and Training, 70(1), 148- 166.

South Africa. Department of Education. (2007). Higher Education Qualifications Framework. October 5. Pretoria: Government Printer.

Wheelahan, L. (2010). "Why knowledge matters in curriculum: A social realist argument". London: Routledge.

Williamson, A. (1997). "Reflection in Adult Learning with Particular Reference to Learning-in-Action. Australian Journal of Adult and Community Education, vol. 37(2) 93-99, 1997.

World Economic Forum. (2016). "The Future of Jobs, Employment skills and workforce strategy for the fourth industrial revolution". 2016. http://www.weforum.org/reports/the-future-of-jobs. Retrieved in June 2019. 